\title{
In situ localisation of Yersinia enterocolitica by catalysed reporter deposition signal amplification
}

\author{
Paul T Odinot, Jacques F G M Meis, J A A Hoogkamp-Korstanje, Willem J G Melchers
}

\begin{abstract}
Aim-The sensitive detection of pathogenic Yersinia enterocolitica in paraffin embedded tissue sections by in situ hybridisation (ISH).

Methods-Y enterocolitica infected cell lines, rat spleens, and patient biopsy specimens were used to compare conventional ISH, immune fluorescence assay (IFA) detection, and catalysed reporter deposition (CARD) signal amplification ISH.

Results-CARD-ISH was shown to be more sensitive then conventional ISH and had a comparable sensitivity to IFA. In contrast to IFA, CARD-ISH preserved good tissue morphology.

Conclusions-CARD-ISH appeared to be a fast and sensitive ISH method for detecting $Y$ enterocolitica in routinely processed tissue sections. Application of this method allows the combination of routine detection and cellular localisation of the pathogen within the infected tissue. (f Clin Pathol 1998;51:444-449)
\end{abstract}

Keywords: Yersinia enterocolitica; in situ hybridisation; in situ localisation

Yersinia enterocolitica is an enteric pathogen which usually causes self limiting gastrointestinal infection. ${ }^{12}$ In some cases infection with this agent can be responsible for chronic and recurrent disorders in humans, such as chronic ileitis, hepatitis, and arthritis. ${ }^{3}$ The presence of serum antibodies against $Y$ enterocolitica (IgG, $\operatorname{Ig} M$, and $\operatorname{IgA}$ ) may reflect the difference between a recently acquired infection, the persistence of the microorganism, or a past infection, ${ }^{45}$ but does not give information on the actual presence of the bacterium. Therefore, the detection of $Y$ enterocolitica in tissue specimens might be important because this could eventually decide which treatment strategy should be followed. Several different detection methods have been described. Most of the techniques rely on culturing the bacterium from the specimen, which is difficult in the chronic stage of the infection, or on the multiplication of specific DNA sequences.

Polymerase chain reaction (PCR) detection of the bacterium is relatively sensitive and specific, although in the case of $Y$ enterocolitica a combination of culture and PCR is often required to increase the sensitivity of detection. ${ }^{6-10}$

An alternative is immune fluorescence assay (IFA) detection with serotype specific antibodies. ${ }^{1}$ The IFA technique is highly sensi- tive, and detection of the pathogen in routinely fixed and paraffin embedded sections can be performed. Despite the disadvantages of IFA, such as loss of tissue morphology and the need for several different antibodies to detect the different $Y$ enterocolitica serotypes, it is the most commonly used technique for detecting $Y$ enterocolitica.

The advantage of in situ hybridisation (ISH) is the detection of the pathogen within the tissue while the tissue morphology remains preserved. In spite of the fact that conventional ISH is very specific, its sensitivity is limited and additional amplification of the signal is often required. Several techniques have been described to increase the sensitivity of ISH. Amplification of ISH signal can be performed with normal immunohistochemical amplification methods such as avidin-biotin complexes or enzyme labelled antibodies, but sensitivity is often still not sufficient. ${ }^{11}$ PCR-ISH uses the principles of PCR by amplifying the target sequence directly in tissue sections, and it appears to be highly sensitive. ${ }^{12}{ }^{13}$ The catalysed reporter deposition (CARD) amplification method creates a deposition of biotinylated tyramine at the place of the hybridised probe and amplifies the hybridisation signal. The biotinylated tyramine can be visualised with a fluorochrome or enzyme labelled avidin. ${ }^{14}$ We applied the CARD-ISH technique for the detection of $Y$ enterocolitica in paraffin embedded tissue sections.

\section{Methods}

BACTERIA

$Y$ enterocolitica serotype O:8 strain WA (ATCC 9610) harbouring the virulence plasmid was grown overnight at $26^{\circ} \mathrm{C}$ in brain-heart infusion broth followed by growth for four hours at $37^{\circ} \mathrm{C}$. The culture was subsequently washed with phosphate buffered saline (PBS) before infection of Caco-2 cells and Fischer 344 rats. In addition, an overnight culture was directly used for the isolation of the $70 \mathrm{~kb}$ $Y$ enterocolitica virulence plasmid (pYV). ${ }^{15}$ Isolation was performed with the Wizard Plus minipreps DNA purification system according to the manufacturer's instructions (Promega, Madison, Wisconsin, USA).

\section{CACO-2 CELL LINE}

Human colon carcinoma derived Caco- 2 cells ${ }^{16}$ were grown to confluency on surfactant-free nitrocellulose membrane filters $(12 \mathrm{~mm}$ diameter, $0.4 \mu \mathrm{m}$ pore size, Costar, Cambridge, Massachusetts, USA) placed in 24 well tissue culture plates (Costar) in Dulbecco's modified Eagle's medium (DMEM, Sigma, St Louis, 
Missouri, USA) without antibiotics, supplemented with $20 \%$ heat inactivated fetal calf serum, and $1 \%$ non-essential amino acids. Cells were incubated at $37^{\circ} \mathrm{C}$ and $90 \%$ relative humidity in air containing $5 \% \mathrm{CO}_{2}$. The medium was added to both the apical and basolateral sides of the cells and was changed daily.

PBS washed bacterial suspensions of $2 \times 10^{8}$ $\mathrm{CFU} / \mathrm{ml}$ in DMEM without supplements were made and $0.5 \mathrm{ml}$ of this suspension was added to the apical side (brush border) of Caco-2 cells. Cells with bacteria were incubated at $37^{\circ} \mathrm{C}$ for six hours and formalin fixed and paraffin embedded for light microscopy.

\section{EXPERIMENTALLY INFECTED RATS}

Fischer 344 rats (Central Animal Laboratory, Nijmegen, The Netherlands) were intravenously infected with $10^{4} \mathrm{CFU}$ in $0.2 \mathrm{ml} 0.9 \%$ saline $Y$ enterocolitica WA O:8 (ATCC 9610). ${ }^{17}$ A control Fischer 344 rat was injected with saline. Fourteen days after infection, rats were killed and their spleens were removed. The tissues were formalin fixed and paraffin embedded for light microscopy.

HUMAN BIOPSY SPECIMENS

Biopsy specimens from two patients with a proven $Y$ enterocolitica infection were formalin fixed and paraffin embedded for light microscopy. Positive $Y$ enterocolitica infection was proven by positive anti-Yop serology (as described earlier ${ }^{18}$ ) and positive immune fluorescence assay (IFA, see below). An abdominal lymph node biopsy from a patient with a mild infection ( $Y$ enterocolitica serotype O:5,27 or O:9), and a stomach biopsy from the other patient who had a severe infection ( $Y$ enterocolitica O:3) were available. Colon biopsies of two patients with Crohn's disease were used as negative control biopsy specimens.

DNA PROBES FOR IN SITU HYBRIDISATION

The pYV plasmid and the pBR322 plasmid were biotin-14-dATP labelled by nick translation with the BioNick Labelling System according tot the manufacturer's instructions (GibcoBRL, Life Technologies, Gaithersburg, Maryland, USA), generating biotin labelled DNA fragments of 100 to $500 \mathrm{bp}$ in size.

PREPARATION AND PRETREATMENT OF SAMPLES FOR IN SITU HYBRIDISATION

Formalin fixed, paraffin embedded $4 \mu \mathrm{m}$ tissue sections of the Caco- 2 cell line, rat spleens, and human biopsy specimens were mounted on SuperFrost Plus coated and positively charged glass slides (Menzel-Gläser, Germany) and heated overnight at $60^{\circ} \mathrm{C}$. After dewaxing in xylene and rinsing in methanol the endogenous peroxidase activity was blocked for 15 minutes at room temperature in $1 \% \mathrm{H}_{2} \mathrm{O}_{2}$-methanol. Slides were then rinsed in methanol and air dried. Samples were incubated for five minutes in $1 \mathrm{M} \mathrm{NaSCN}$ at $80^{\circ} \mathrm{C}$ and five minutes in demineralised water at $37^{\circ} \mathrm{C}$, and then with $8000 \mathrm{U} / \mathrm{ml}$ pepsin (Sigma) in $0.2 \mathrm{M} \mathrm{HCl}$ at $37^{\circ} \mathrm{C}$ to create good accessible target DNA for the ISH probes. The optimal pepsin digestion time was checked for each paraffin embedded tissue sample individually, starting with a time range of 1 to 10 minutes. The digestion times are critical as loss of morphology owing to section digestion can occur. Next, the slides were rinsed in demineralised water and dehydrated in an increasing alcohol range. Again endogenous peroxidase was blocked with $1 \% \mathrm{H}_{2} \mathrm{O}_{2}$ in methanol, mainly to inactivate the endogenous enzymes within tissue red blood cells, polymorphonuclear leucocytes, and macrophages. Subsequently the sections were air dried after rinsing in methanol.

IN SITU HYBRIDISATION AND IMMUNOCHEMICAL DETECTION

The $Y$ enterocolitica plasmid probe was hybridised to the paraffin sections at a probe concentration of $2 \mathrm{ng} / \mu$ l hybridisation mixture $(60 \%$ deionised formamide (Merck, Darmstadt, Germany), 10\% dextran sulphate (Sigma), $2 \times$ SSC pH $7.0(1 \times \mathrm{SSC}=0.15 \mathrm{M} \mathrm{NaCl} / 0.015 \mathrm{M}$ $\mathrm{Na}$ citrate)), and $50 \mathrm{ng} / \mu \mathrm{l}$ herring sperm DNA (Boehringer Mannheim, Mannheim, Germany). Twenty microlitres of probe mixture were applied to the sections under a coverslip $(24 \times 50 \mathrm{~mm})$ and sealed with rubber cement. Probe and target DNA were denatured at $80^{\circ} \mathrm{C}$ for 10 minutes in a moist chamber. After overnight hybridisation at $37^{\circ} \mathrm{C}$, the coverslips were removed by immersing the slides in $2 \times$ SSC at $42^{\circ} \mathrm{C}$. Post-hybridisation washes were carried out twice in $60 \%$ deionised formamide in $2 \times$ SSC for five minutes and twice in $2 \times$ SSC for five minutes at $42^{\circ} \mathrm{C}$. Next, the sections were rinsed in phosphate buffered saline with $0.05 \%$ Tween-20 (Sigma) (PBST) at room temperature.

The horse radish peroxidase labelled $A B C$ method was applied for the detection of the biotinylated probe in the sections, ${ }^{11}$ using the Elite ABC kit (Vector Laboratories, Burlingame, California, USA). Incubations were performed for 30 minutes at $37^{\circ} \mathrm{C}$. PBST containing $1 \%$ non-fat dry milk (Protifar, Nutricia, The Netherlands) (PBSTM) was used for all incubation steps. All washing steps between the incubations were three times in PBST for five minutes at room temperature. For blocking non-specific signals the tissue sections were preincubated with PBSTM for 15 minutes at $37^{\circ} \mathrm{C}$. Next, mouse antibiotin (1:100, Boehringer Mannheim), biotinylated horse antimouse (1:200, Hs $\alpha$ M-bio, Vector), and ABC (avidin 1:100, biotin-peroxidase $1: 100$, Vector) were applied. After rinsing in PBST and PBS, demonstration of horse radish peroxidase was accomplished by precipitating 3,3'-diaminobenzidine tetrahydrochloride (DAB, Pierce, Rockford, Illinois, USA) through the reaction of $\mathrm{H}_{2} \mathrm{O}_{2}$ (Merck) with horse radish peroxidase. Sections were incubated with $0.05 \% \mathrm{DAB} / 0.15 \% \mathrm{H}_{2} \mathrm{O}_{2}$ in $\mathrm{PBS}$ with $0.65 \%$ imidazole (Merck) for five minutes. After rinsing in demineralised water, the $\mathrm{DAB}$ signal was amplified with $0.5 \% \mathrm{CuSO}_{4}$ in $0.9 \% \mathrm{NaCl}$ for one minute and sections were again rinsed in demineralised water. Sections were counterstained with Mayer's haematoxylin and eosin. Finally, the sections were 


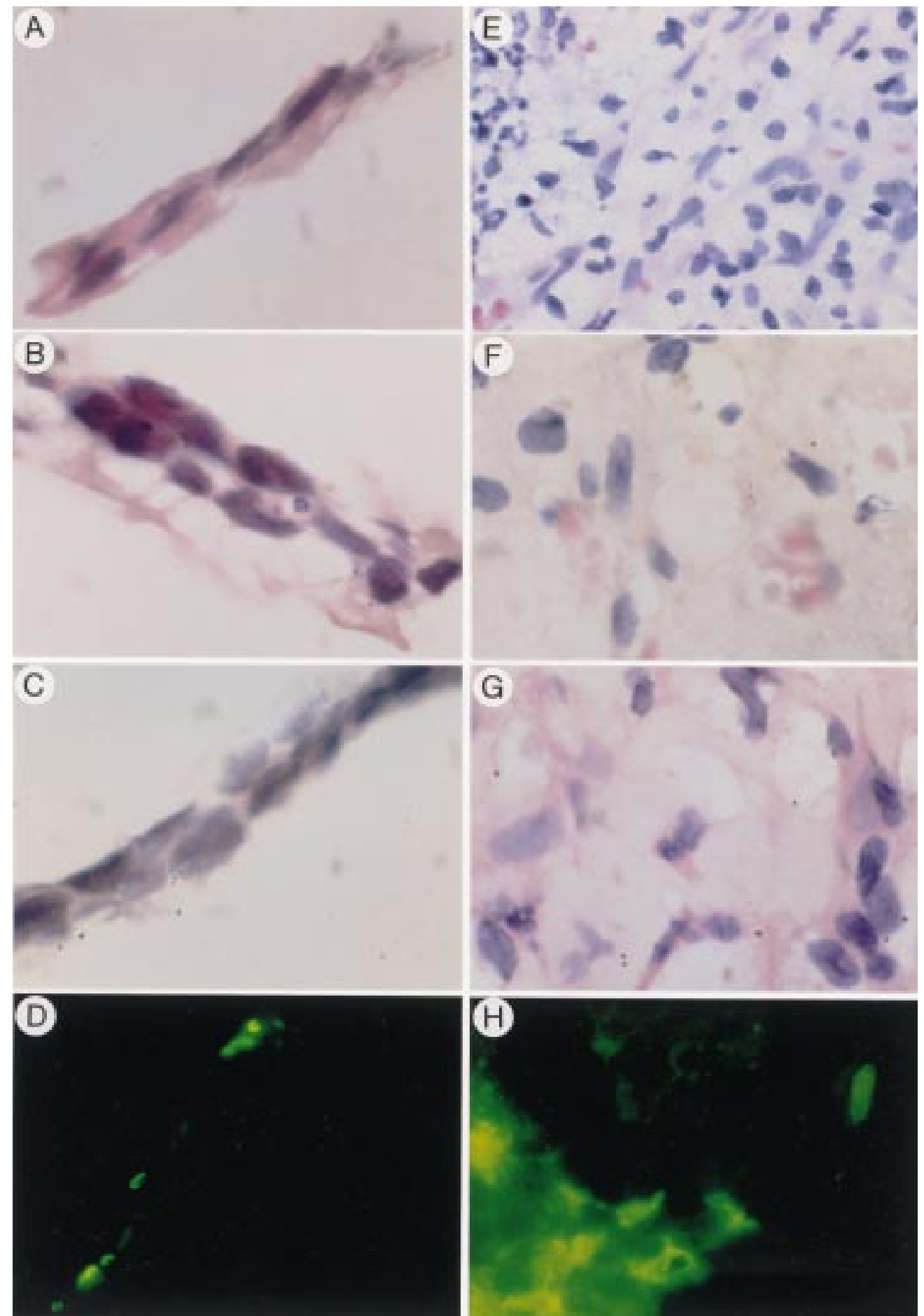

Figure 1 Results of ISH, CARD-ISH, and IFA on paraffin wax sections of infected Caco-2 cells and rat spleen. (A)-(D), Y enterocolitica serotype O:8 strain WA (ATCC 9610) infected Caco-2 cell line; $(E)-(H), Y$ enterocolitica serotype O:8 strain WA (ATCC 9610) infected rat spleen; $(A)$ and (E), control CARD-ISH with pBR322 probe; (B) and $(F)$, normal ISH with $p Y V$ probe; $(C)$ and $(G), C A R D-I S H$ with $p Y V$ probe; $(D)$ and $(H)$, IFA with a $Y$ enterocolitica serotype O:8 mouse monoclonal antibody. All preparations were briefly counterstained with Mayer's haematoxylin and eosin.

mounted in Permount (Fisher Scientific, Fair Lawn, New Jersey, USA).

CATALYSED REPORTER DEPOSITION (CARD)-ISH SIGNAL AMPLIFICATION

A normal ISH and ABC method (as described above) was used up to the DAB detection. Before amplification with the CARD-ISH signal amplification method, biotinylated tyramine (BT) was made up as previously described by Kerstens et al. ${ }^{14}$ For the CARDISH signal amplification, BT was precipitated through the enzymatic reaction of horse radish peroxidase. The specimens were incubated with BT-PBS and $0.01 \% \mathrm{H}_{2} \mathrm{O}_{2}$ for five minutes at room temperature. The BT concentration was $0.7 \mu \mathrm{M}$. After rinsing in PBST, the biotin precipitate was detected with a second incuba- 

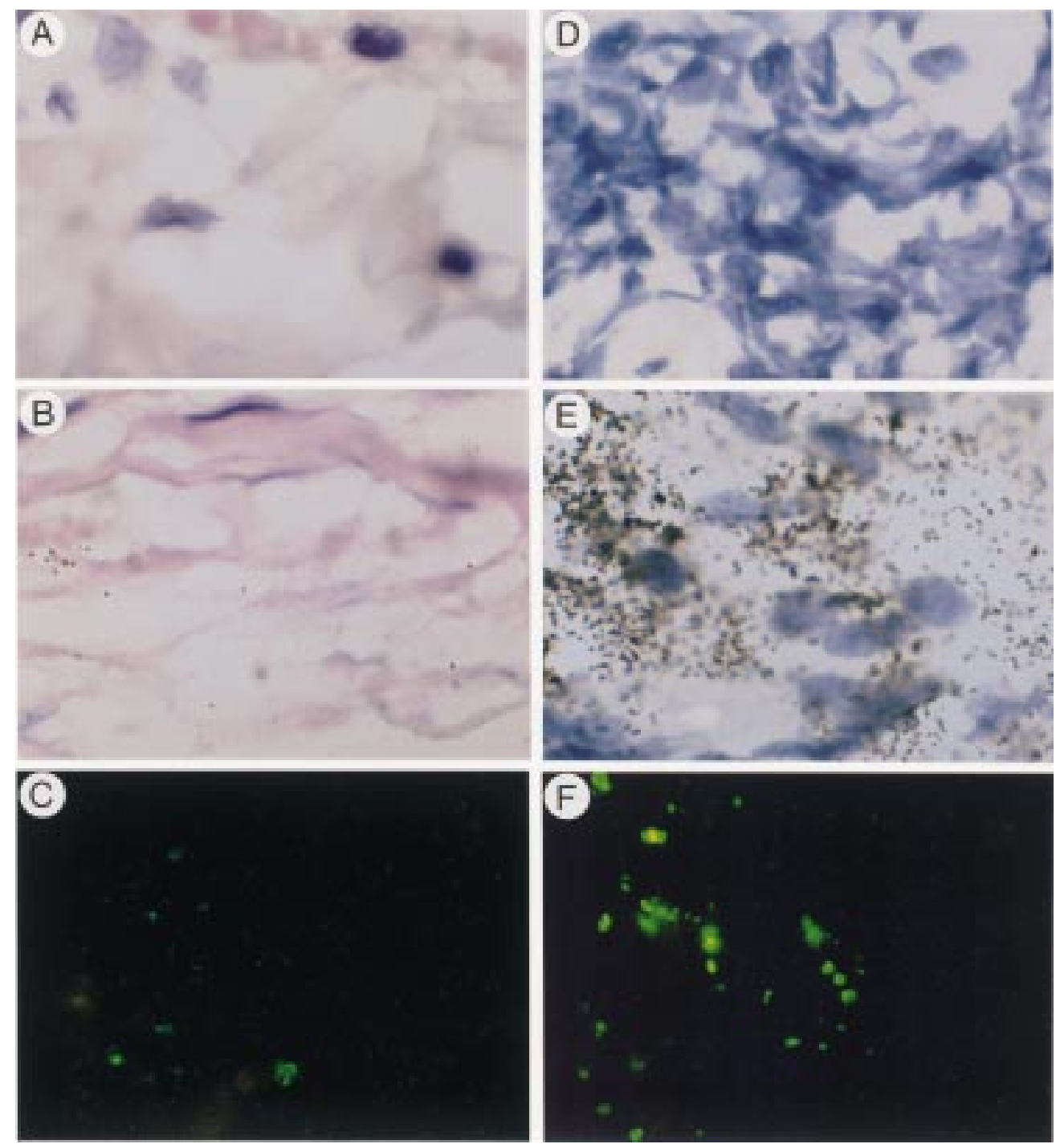

Figure 2 Results of CARD-ISH and IFA on paraffin wax sections of clinical biopsy specimens from two patients with a $Y$ enterocolitica infection. $(A)-(C)$, lymph node biopsy specimen from a patient with a mild $Y$ enterocolitica infection; (D) - $(F)$, stomach biopsy specimen from a patient with a more severe $Y$ enterocolitica infection; $(A)$ and (D), control $C A R D-I S H$ with $p B R 322$ probe; $(B)$ and $(E), C A R D-I S H$ with $p Y V$ probe; $(C)$ and $(F)$, IFA with a Y enterocolitica serotype cross reactive antibody against serotypes O:3, O:5,27, and O:9. All preparations were briefly counterstained with Mayer's haematoxylin and eosin.

tion of ABC (dilute ABC complex 1:4) for 20 minutes at $37^{\circ} \mathrm{C}$. After rinsing in PBST and PBS, horse radish peroxidase was demonstrated as described above.

IMMUNE FLUORESCENCE ASSAY

Sections from the same tissues as described above were deparaffinated and treated with protease XIV $(0.0125 \%$, Sigma) in PBS for 30 minutes at $37^{\circ} \mathrm{C}$. Mouse monoclonal antibodies against $Y$ enterocolitica serotypes $\mathrm{O}: 8$ and $\mathrm{O}: 3$, and a cross reactive antibody against serotypes $\mathrm{O}: 3, \mathrm{O}: 5,27$, and $\mathrm{O}: 9$, in dilutions of $1: 25,1: 20$, and 1:20 respectively in PBS were added, followed by addition of fluorescein isothiocyanate (FITC) conjugated rabbit antimouse immunoglobulins (1:100, Dakopatts, Glostrup, Denmark). ${ }^{1}$ Both monoclonal antibodies showed clear, sharp cell wall fluorescence.

\section{Results}

The CARD-ISH detection of $Y$ enterocolitica in infected Caco-2 cells and rat spleen was compared with ISH and IFA on parallel sections (fig 1). When using ISH with the conventional ABC method, weak hybridisation signals were observed in both infected Caco-2 cells and rat spleen (fig 1, B and F). After application of the CARD-ISH method, clear hybridisation signals and additional hybridisation signals were observed (fig 1, C and G). IFA showed a similar sensitivity as CARDISH, although with IFA a loss of tissue morphology was observed (fig 1, D and $\mathrm{H}$ ). When biotinylated pBR322 was used as control probe no hybridisation signals were observed in infected Caco-2 cells and rat spleen (fig 1, A and $\mathrm{E}$ ).

Figure 2 shows the results of CARD-ISH and IFA on parallel human biopsy tissue sections of two patients infected with $Y$ entero- 
colitica. Patient 1 (fig 2, A-C) had a mild infection in an abdominal lymph node, and patient 2 (fig 2, D-F) had a severe infection in the stomach. A CARD-ISH control with biotinylated pBR322 as probe is shown in fig 2, panels $A$ and $D$. No hybridisation signal was observed in either panel. The CARD-ISH with the $Y$ enterocolitica virulence plasmid as probe is shown in fig 2, panels B and E. Panel B shows a small focus of infection and some solitary bacteria, while panel $\mathrm{E}$ shows a large focus of infection. Panels $\mathrm{C}$ and $\mathrm{F}$ in fig 2 show the IFA detection of $Y$ enterocolitica. This IFA detection showed similar results to the CARD-ISH detection, but with loss of tissue morphology.

As negative controls, colon biopsies of two patients with Crohn's disease were analysed. IFA was performed to compare the signals with the CARD-ISH. Both IFA and CARD-ISH were negative. No CARD-ISH signal was observed in the surrounding tissue or in normal intestinal flora (data not shown).

\section{Discussion}

The detection of bacteria in routinely fixed tissue samples for light microscopy is still hampered by the low sensitivity and specificity of the methods available. IFA is still the most commonly used routine method for detecting $Y$ enterocolitica. However, IFA requires different $Y$ enterocolitica serotype specific antibodies, ${ }^{1}$ and tissue morphology is completely lost. For ISH a single probe can be used to detect different serotypes, while tissue morphology is generally well preserved. On the other hand, the sensitivity of ISH is limited. To improve the sensitivity of this method several immunohistochemical amplification methods have been developed. Sequential incubations with various antibodies are performed or else the most sensitive current immunohistochemical signal amplification technique - the horseradish peroxidase labelled avidin-biotin complex (ABC) technique - is applied to increase the sensitivity. ${ }^{11}$ Although both methods result in higher sensitivity, it is still often insufficient.

Another option is to combine immunohistochemical amplification with a multicopy target or with probes ranging from several kilobases up to the size of the total bacterial genome. ${ }^{19} 20$ This combined ISH method has already been applied successfully for the detection of different human pathogens, for example Helicobacter pylori, Chlamydia trachomatis, Leishmania, Plasmodium falciparum, and various different viruses. ${ }^{20-24}$ However, in cases when only probes of 30 to 50 bases can be used or when the accessibility of the DNA target is poor, the sensitivity of ISH remains a limiting factor. In addition, in order to detect bacteria long enzyme digestions are generally required to obtain good accessible target DNA; while this results in optimal hybridisation it also leads to a loss of tissue morphology. To circumvent these problems enhanced amplification is necessary.

Recently, amplification methods have been described which increase the sensitivity of the ISH. The PCR-ISH is based on the amplification of nucleic acids in the tissue section, directly followed by a normal ISH. ${ }^{12}$ The CARD-ISH on the other hand, starts with a normal ISH, after which the detection signal is amplified. ${ }^{1425}$ Both methods allow the detection of a single copy of the human papilloma virus (HPV) 16 in SiHa cells with similar sensitivity, while normal ISH was limited by a threshold of 20 copies per cell. ${ }^{125}$ Furthermore, both CARD-ISH and PCR-ISH can be performed within 24 hours. Although the sensitivity of both methods is similar and both are rapid, expensive equipment and reagents are required for PCR-ISH while for CARD-ISH, normal ISH and routine immunohistochemical reagents and equipment can be used, making the CARD-ISH method more applicable for routine settings.

Zehbe et al recently described a modified CARD-ISH method in which they used a nanogold label with silver acetate autometallography to visualise the probe. ${ }^{26}$ With this modified CARD-ISH method the sensitivity for the detection of HPV 16 in SiHa cells was similar to that achieved when enzymatic detection was used for visualisation. However, the signals were sharper and contrast was increased compared with enzymatic detection, resulting in better ability to judge positivity. Moreover, for pathophysiological studies, this modified CARD-ISH can be very useful since gold and silver are very electron-dense, which allows the use of the CARD-ISH in electron microscopy.

Detection of $Y$ enterocolitica in cases of chronic infection and extraintestinal complications is almost impossible. ${ }^{127}$ In these cases the organism disappears from the circulation and hides within the gut associated lymphoid tissue and other lymphoid tissues. ${ }^{3}$ The only direct detection of the bacterium then possible is in biopsy samples. The CARD-ISH system appears to be a good molecular tool to demonstrate $Y$ enterocolitica within infected tissues and provides direct information of the presence of $Y$ enterocolitica in such tissues. Furthermore, the CARD-ISH system can be used to gain knowledge about the pathophysiology of $Y$ enterocolitica infections.

1 Hoogkamp-Korstanje JAA, de Koning J, Samsom JP. Incidence of human infection with Yersinia enterocolitica serotypes $\mathrm{O} 3, \mathrm{O} 8$, and $\mathrm{O} 9$ and the use of indirect immunofluorescence in diagnosis. $\mathcal{F}$ Infect Dis 1986;153:138-41.

2 Cover TL, Aber RC. Yersinia enterocolitica. $N$ Engl $7 \mathrm{Med}$ 1989;321:16-24.

3 Hoogkamp-Korstanje JAA, de Koning J, Heesemann J. Persistence of Yersinia enterocolitica in man. Infection 1988;16:81-5

4 Bottone EJ. Yersinia enterocolitica: the charisma continues. Clin Microbiol Rev 1997;10:257-76.

5 Maki-Ikola O, Heesemann J, Toivanen A, et al. High frequency of Yersinia antibodies in healthy populations in Finland and Germany. Rheumatol Int 1997;16:227-9.

6 Odinot PT, Meis JFGM, Curfs JHAJ, et al. Two-step Odinot PT, Meis JFGM, Curfs JHAJ, et al. Two-step
polymerase chain reaction assay for detection of Yersinia species in general and of pathogenic Yersinia enterocolitica specifically. Int F Infect Dis 1997;1:206-11.

7 Harnett N, Lin YP, Krishnan C. Detection of pathogenic Yersinia enterocolitica using the multiplex polymerase chain reaction. Epidemiol Infect 1996;117:59-67.

8 Ibrahim A, Liesack W, Stackebrandt E. Polymerase chain reaction-gene probe detection system specific for pathogenic strains of Yersinia enterocolitica. 7 Clin Microbiol 1992;30:1942-7.

9 Kapperud G, Vardund T, Skjerve E, et al. Detection of pathogenic Yersinia enterocolitica in foods and water by immunomagnetic separation, nested polymerase chain reactions, and colorimetric detection of amplified DNA. Appl Environ Microbiol 1993;59:2938-44. 
10 Wren BW, Tabaqchali S. Detection of pathogenic Yersinia enterocolitica by the polymerase chain reaction. Lancet 1990;336:693.

$11 \mathrm{Hsu}$ SM, Raine L, Fanger H. Use of avidin-biotinperoxidase complex (ABC) in immunoperoxidase techniques: comparison between $\mathrm{ABC}$ and unlabeled antibody (PAP) procedures. I Histochem Cytochem 1981;29: 577-80.

12 Nuovo GJ, MacConnell P, Forde A, et al. Detection of human papillomavirus DNA in formalin-fixed tissues by in situ hybridization after amplification by polymerase chain reaction. Am 7 Pathol 1991;139:847-54

13 Nuovo MA, Nuovo GJ, MacConnell P, et al. In situ analysis of Paget's disease of bone for measles-specific PCRamplification cDNA. Diagn Mol Pathol 1992;1:256-65.

14 Kerstens HMJ, Poddighe PJ, Hanselaar AGJM. A novel in situ hybridisation signal amplification method based on the deposition of biotinylated tyramine. $\mathcal{F}$ Histochem Cytochem 1995;43:347-52.

15 Cornelis G, Biot T, Lambert de Rouvroit C, et al. Genetics of YOP production in Yersinia enterocolitica. In: Ron EZ, Rottem S, eds. Microbial surface components and toxins in Rottem S, eds. Microbial surface components and toxins in
relation to pathogenesis. New York: Plenum Press, 1991: relation

16 Pinto M, Robine-Leon S, Appay M, et al. Enterocyte-like differentiation and polarization of the human colon carcinoma cell line Caco-2 in culture. Biol Cell 1983;47: 323-30.

17 Odinot PT, Curfs JHAJ, Meis JFGM, et al. Local expression of cytokine mRNA in spleen and Peyer's patches of rats is involved in resistance against infection with Yersinia enterocolitica. Cytokine (in press)

18 Curfs JHAJ, Meis JFGM, Van der Lee HAL, et al. Persistent Yersinia enterocolitica infection in three rat strains. Microb Pathog 1995;19:57-63.
19 Van den Berg FM, Zijlmans H, Langenberg W, et al. Detection of Campylobacter pylori in stomach tissue by DNA in situ hybridisation. F Clin Pathol 1989;42:995-1000.

20 Bashir MS, Lewis FA, Quirke P, et al. In situ hybridisation for the identification of Helicobacter pylori in paraffin wax embedded tissue. 7 Clin Pathol 1994;47:862-4.

21 Beutler AM, Schumacher HRJ, Whittum-Hudson JA, et al. In situ hybridization for detection of inapparent infection with Chlamydia trachomatis in synovial tissue of a patient with Reiter's syndrome. Am f Med Sci 1995;310:206-13.

22 van Eys GJ, Schoone GJ, Ligthart GS, et al. Detection of Leishmania parasites by DNA in situ hybridization with non-radioactive probes. Parasitol Res 1987;73:199-202.

23 Van den Berg FM, Van Amstel PJ, Janse CJ, et al. Detection of different developmental stages of malaria parasites by non-radioactive DNA in situ hybridization. Histochem $\mathcal{f}$ 1991;23:109-15.

24 Unger ER, Lee DR. In situ hybridization: principles and diagnostic applications in infection. F Histotechnol 1995;18: 203-9.

25 Poddighe PJ, Bulten J, Kerstens HMJ, et al. Human papilloma virus detection by in situ hybridisation signal amplification based on biotinylated tyramine deposition. $f$ Clin Pathol Mol Pathol 1996;49:M340-4.

26 Zehbe I, Hacker GW, Su H, et al. Sensitive in situ hybridization with catalyzed reporter deposition, streptavidinnanogold, and silver acetate autometallography. $\mathrm{Am} \mathcal{f}$ Pathol 1997;150:1553-61.

27 de Koning J, Heesemann J, Hoogkamp-Korstanje JAA, et al. Yersinia in intestinal biopsy specimens from patients with seronegative spondyloarthropathy: correlation with specific serum IgA antibodies. F Infect Dis 1989;159:109-12. 